\title{
Evolving Concepts Related to Achieving Benefit Sharing for Custodians of Traditional Knowledge
}

\author{
Memory Elvin-Lewis
}

\section{Theory}

\begin{abstract}
In the context of evolving intellectual property law, defining ownership of traditional knowledge can be challenging when claims of origin are conflicting and requires accepting parameters of how uniqueness is defined and patent law is applied to protect this information. For purposes of this paper, the complexities of evolving benefit sharing for custodians of traditional knowledge are discussed in relationship to the use of medicinal plants. Parameters of ownership can vary not only by the perception of individuals that lay claim to the information but also by international, regional and national laws that govern how benefits should be fairly appropriated. Examples are provided to exemplify the wide variation that presently exists in this evolving process with illustrations of how this information, novel or otherwise, can be utilized to optimize its commercial worth.
\end{abstract}

\section{Introduction}

Unlike a decade ago, changing laws and policies are globally affecting the way traditional knowledge is valued and protected. The need for this has evolved as custodians of these data are becoming aware that this type of information may amount to a commodity, which requires appropriate recording, protection and management. In the current climate of rapid acculturation and globalization, understanding these aspects is paramount, particularly since so much valuable information is rapidly disappearing. Within this context, suitable types of benefit sharing can only be achieved if appropriate mechanisms are in place to prevent exploitation should commercialization evolve. This paper is designed to provide current insights into the complex and evolving process of deriving fair compensation for current holders of traditional knowledge (TK), using as the primary example, cultural nuances related to the timehonored uses of medicinal plants.

Fundamental to this on-going process was the establishment of the United Nations Framework Convention on Biodiversity (CBD) at the Earth Summit in Rio de Janeiro in 1992 (Table 1). The CBD evolved out of global concerns regarding the reduction of biological diversity through human activity and the need to reverse this trend for the benefit of present and future generations. Its goals are to conserve biological diversity, ensure the sustainable use of its components, reaffirm that States have sovereign rights over their own biological resources, and ensure the fair and equitable sharing of the benefits from the use of genetic resources, particularly as it is linked to the traditional knowledge of indigenous people. It further requires that access to and transfer of biological resources and relevant technologies can only occur with "prior and informed consent" of member States and those populations that apply these in their TK systems. It has the

\section{Correspondence}

Memory Elvin-Lewis, Washington University, St. Louis, 63130. U.S.A.

elvin@biology.wustl.edu

Ethnobotany Research \& Applications 4:075-096 (2006) 
Table 1. Convention on Biological Diversity (CBD), 1992. Issues related to environmental law and policy making.

- Conservation of biological diversity

- Sustainable use of the components

- Fair and equitable sharing of benefits

- Access to genetic resources

- Transfer of relevant technologies

- Consideration of all rights over these resources and technologies

- Availability of appropriate funding to develop these issues

All signatories are required to respect, preserve, and maintain the knowledge, innovations, and practices of the indigenous communities.

overwhelming support of the majority of the world's nations, with the exception of a few others including the United States (Posey \& Dutfield 1996). While signed by United States President Clinton, the CBD has yet to be ratified by the United States Congress because it is viewed as impairing American intellectual property rights as a constraint to the transfer of technology rather than as a prerequisite (McManis 2003). Moreover, without methods to enforce compliance with its directives, it is considered a "toothless declaration of good intentions," with much of its treaty language being persuasive rather than mandatory (McManis In Press). Nonetheless, activities of its signature nations within the context of the CBD continue to address problems of mutual concern and, in spite of its obvious shortcomings, its policies are likely to promote goodwill and positive influences among countries that prescribe to its intent. The signature nations continue to work on the implementation of Article 8(j) which obligates members to "respect, preserve and maintain knowledge, innovations and practices of indigenous and local communities embodying traditional lifestyles relevant to the conservation and sustainable use of biological diversity; promote their wider application with the approval of the holders of such knowledge, innovations and practices; and encourage the equitable sharing of benefits arising from the utilization of such knowledge, innovations and practices."

To complement these efforts and to facilitate these activities, another specialized international government organization, the World Intellectual Property Organization (WIPO), was evolved from the United International Bureaux for the protection of Intellectual Property. This organization consists of 183 member states to date and has established an Intergovernmental Committee on Intellectual Property and Genetic Resources, Traditional Knowledge and Folklore (McManis 2003).

When the World Trade Organization (WTO) was established in 1994, a number of international agreements, including those incorporated into the Agreement on Trade Related Aspects of Intellectual Property (commonly called the TRIPS Agreement) were evolved to define minimal international standards for intellectual property management and enforcement. With the exception of a few less developed nations, full compliance with its mandates, including its controversial patent and plant variety provisions, has existed since 2005. In order to enforce compliance, the WTO will work to resolve contentious issues and impose multilateral trade sanctions when necessary (McManis In Press). To insure that the concepts of the CBD are addressed in the context of the TRIPS agreement, the Doha Declaration was formulated at the Fourth Ministerial Conference in Doha, Qatar in 2001. So that sustainable biodiversity is assured during its use to promote health and economic development, the TRIPS Council was instructed to give "particular attention to the protection of traditional knowledge and folklore, and to take into account the stated objective of TRIPS to contribute to the promotion of technological innovation and transfer and dissemination of technology, to the mutual advantage of producers and users of technological knowledge, and in a manner conducive to social and economic welfare" (McManis 2003).

There are a number of challenges to overcome to accommodate this development of evolving suitable intellectual property laws. For example, defining claims of ownership is intricate when claims of origin are conflicting and requires accepting parameters of how new sui generis TK protection or "of its own kind" is defined and trade secrets, trademark and patent law are applied to protect this information. Because each nation and group may view claims to tangible and intangible resources differently, there is not any standard design for this type of effort. Recognizing that the need is urgent, wide spread global efforts are being made to define workable and satisfactory solutions to this complex and ever-evolving task.

\section{What is Traditional Knowledge?}

In a broader perspective, an understanding of what traditional indigenous knowledge means is necessary (Zhang 2000). We are all recipients of various types of information and its acquisition is a continuing and dynamic process. Each individual's knowledge is composite in nature and reflects what is acquired from various sources and a lifetime of experiences. Its content is dictated by both cultural and temporal parameters, its relevance to our daily lives, and its relevant value. Depending on contact with others, similarities of data can be found among families, communities, and beyond.

As mobility and globalization have increased, absorption elsewhere is inevitable, with changes of use often evolving along the way. Examples can be found in all facets of our daily lives whether it is in methods of healing or in other applied or cultural aspects relevant to every day creative endeavors. 


\section{Elvin-Lewis - Evolving Concepts Related to Achieving Benefit Sharing for Custodians of Traditional Knowledge}

Generally, the uniqueness of traditional knowledge (TK) is defined as being evolved, preserved, and transmitted in long-established ways between generations with the originators of its derivation becoming obscured over time. According to Koopman (2005b), it is also defined as "coming forth from holistic cosmologies and from very particular methodologies (i.e., hands-on experience, intuitive approaches and use of diachronic data). TK combines different types of propositional knowledge (e.g., science, spirituality) and the same prescriptive (applications, technology) knowledge types. It also broadly combines the propositional with the prescriptive, and thus entails a holistic model." This information may be associated with a community, clan, and tribe through a sense of custodianship, guardianship or cultural responsibility and its exclusivity is often circumscribed to either a particular indigenous or non-indigenous local group or groups. However, if cultural groups and floras regionally overlap, some information may be widely dispersed (or widely held) within this broader context but otherwise not necessarily well known elsewhere. As such, it may be considered the collective knowledge (CK) of groups from one or more nations. However, one cannot presume that all uses have arisen from the original inhabitants of a particular region. Contact with other peoples and their plants can also impact on how certain pharmacopeias evolve. Therefore, the uniqueness of TK or CK associated with medicinal plants can only be defined within the parameters of people, places, nations, and floras. It is important to appreciate that what is considered as traditional knowledge is an ever-evolving process. Access to other information, introduction of plants not indigenous to a region, natural inventiveness, as well as changing disease patterns, can all impose modifications on use and preference (Elvin-Lewis 2006; Lewis et al. 1991, Lewis et al. 2004, Milanowski et al. 2002). Thus, the acquisition of these types of data and estimations of perceived worth has to be placed into a temporal context as well.

The CBD conveys national sovereignty (not ownership) over genetic resources, and obliges states that have ratified this convention to (1) acknowledge the cultural interest of TK holding communities in their knowledge, (2) recognize their interest in remaining involved in potential industrial uses thereof, and (3) to share commercial benefits arising out of utilization of this knowledge. One of the difficulties with the CBD is that it does not convey any property-like rights to TK holders, but only recognizes their cultural relation and interest therein, as well as a right to receive benefits - which is more a tailored extractive right than a property right (Koopman personal communication). Sovereignty issues related to CK are less clear and would depend if this knowledge is nationally circumscribed or more regionally known. As will become evident further on in this paper, this has not prevented certain countries and regional associations to evolve certain laws and polices, related to "ownership or sovereignty" of both their genetic resources and knowledge associated with their uses.
Guardianship of specific types of traditional medicinal knowledge can vary widely. It may be carefully preserved within a family, known to specialized healers or to one gender, shared among community members, clans and tribes, or generally known in a regional context. In certain cases, as with many traditional healers in sub Sahara Africa, this information is closely guarded because like trade secrets they are perceived as being valuable assets which can assure a practitioner's livelihood. Also, cultural practices and the "need to know" may often dictate if this knowledge is widespread or circumscribed to only a few specialized individuals within a community setting (e.g., African bonesetters). Elsewhere, knowledge of healing may be passed along through forms of apprenticeship or training to those expressing their willingness to utilize and/or practice it. These individuals may provide their services for profit or provide them freely to the community. Representative of this group are the "curandaros" of the neotropics or healers of Oceania. In Amazonian villages most adults are generally familiar with the use of most medicinal plants in their pharmacopeia and women are especially knowledgeable of those herbal remedies needed for themselves or their children. In this setting, shamans or brujos (witches - not to be confused with curandaros), are a specialized group of individuals who utilize psychoactive plants (often only for themselves) for the purposes of diagnosis and treatment. Their value as healers is very much intertwined with local cosmic beliefs and their ability to remove the "invisible" dart that is considered the basis for a wide range of indefinable ailments. They frequently combine forms of energy medicine in the form of mantras with their "psychic" and "tracing" healing practices that are amplified by them taking hallucinogenic potions. Like their African counterparts, or fetish priests, they have a respected status in the community with talents akin to psychiatrists. Alternately, medicine men and women of North American indigenous tribes practice forms of healing that combines the use of medicinal herbs with energy medicine (e.g., repetitive chants or mantras) which may often include eliciting the intersession of their ancestors. These practices can be closely guarded or widespread within a group, tribe, or region.

Usually concepts transmitted orally are more likely to evolve more quickly but nuances of use or formulary variations can fluctuate even within a family unit, such as has been observed among Amazonian populations using hepatitis remedies (Elvin-Lewis et al. 2002), not necessarily secret in a community or constituency; this information may be unknown elsewhere and therefore has value as circumscribed "know-how." Numerous examples of this type of unique knowledge can still be found among isolated indigenous communities of tropical South America.

\section{Claims of Ownership}

Ownership may be viewed differently under customary (indigenous), national and international laws. Claims re- 
lated to a particular interest by local or indigenous groups may be further substantiated if the plants themselves are unique to a particular region, thus restricting further the likelihood of this information being derived from elsewhere. However, when a number of groups have access to the same flora, uses can be similar and overlap, or be quite different depending upon the social interrelationships that have occurred over time and the number of related plant species or genera that share the same types of bioreactivities. The evolution of many pharmacopeias is not static in nature and the derivation of the individuals involved (e.g., in Peru), people of mixed heritage (mestizo), colonist (+500 years primarily of Spanish origin), or indigenous can also dictate how plants are used medically and have resulted in distinctive pharmacopeias being preferred in neighboring Amazonian and Andean communities. To resolve issues of "ownership," similar types of knowledge may be considered as CK or alternately require an agreement between parties making claim to particular forms of exclusive information as to how its disclosure may be mutually beneficial. This is further complicated when there is lack of agreement as how to manage these data or who has the right to divulge it and utilize it for profit in the first place.

This does not mean that the source of traditional knowledge for a medicinal use can always be ascertained. Sometimes the basis of this knowledge is obliterated by widespread application over an undetermined interval of time. This process is enhanced as aculturization and assimilation of cultures proceeds and can even extend beyond the region or nations where the plant and its allies once originated. Several species or chemotypes can be involved that also possess the same or similar active components and thus claims of origin would be difficult to achieve if these taxa are known to be pervasive. A noteworthy example is the use of the sap of the Amazonian tree Croton lechleri and related taxa for wound healing throughout western tropical South America (Milanowski et al. 2002). Also, some plants have such a global distribution and are used for the same purpose that claims of specific ownership would be impossible to validate, such as the use of Maclura tinctoria (L.) Steudel for tooth extraction throughout the tropics of Madagascar, Africa, and South America (Kaufmann \& Elvin-Lewis 1995), the cosmopolitan uses of either Catharanthus roseus (L.) G.Don f. in remedies for diabetes (Lewis \& Elvin-Lewis 2003), or of Phyllanthus species for hepatitis (Elvin-Lewis 2006). To deal with these types of contingencies, when regional parameters can be defined, it has been suggested within the context of the Auckland Declaration of 2004 that a mutual trust to deal with benefit sharing be evolved with the goal of seeking partnerships with area neighbors and beyond so as to develop knowledge, improve communications and ensure a sustainable economic existence for all. Representative nations evolving this declaration include Australia, the Cook Islands, Federated states of Micronesia, Fiji, Kiribati, New Zealand, Niue, Palau, Papua New Guinea, Republic of the Marshall Islands, Samoa, Solomon Is- lands, Tonga, Tuvalu and Vanuatu (Anomymous 2004a). In the other extreme, it is not easy to determine if certain cultivars which are carefully selected and circumscribed for a particular application are related to their specific healing qualities and the nature of their components or simply linked to particular cultural beliefs which specify the fastidious use of a specimen to how its donor perceives its worth for a specific purpose. Numerous examples of this practice exist among Amazonian peoples where cultivars are shared for only one medicinal purpose and a seemingly identical specimen used for another purpose. Also impacting on the evolution of uses are those plant introductions which have occurred since the colonial period. For example, in Peru, ginger (Zingiber officinale L.) and turmeric (Curcuma longa L.), valued in many Asian pharmacopeias, are incorporated into numerous mestizo and indigenous herbal remedies (Elvin-Lewis et al. 2002)

\section{Utilization of Traditional Knowledge in the Public Domain}

Traditional formulations may consist of one plant containing one or more compounds with complementary or different activities or may be an admixture of several plants (referred to as a polyherbal) that are prepared to optimize the efficacy of the treatment. In some pharmacopeias a treatment may also consist of plants are given sequentially (Elvin-Lewis 2005, Elvin-Lewis et al. 2002). Most of these remedies are moderate in potency and low in toxicity thus making them compatible for human use, particularly if used on a short-term basis. As botanicals they may vary widely in composition, potency, and content and thus there are limitations to their efficacy or safety (Elvin-Lewis 2002, 2005, WHO 2000, 2004b, WIPO 2002a, 2005b). Knowledge of their value may be passed along by oral traditions or be properly recorded.

Should commercialization extend beyond the regional collection of wild plant populations and their sale as botanicals in local market places, some forms of control may be necessary to ensure a reliable source (WHO 2002, $2004 a, b)$. For example, national authorities may become involved in ensuring sustainability by monitoring plant removal from the wild, fostering the establishment of plantations, or limiting the export of genetically reproducible material for growth elsewhere. Also, to protect rare plants at risk of extinction from nefarious exploitation by commercial entities, geopositioning data may be redacted from herbarium sheets. Without these policies the existence of valuable plants and the livelihood of local communities could be endangered.

For some parts of the world, particularly in Europe and Asia, much information is already in the public domain through a wide variety of published pharmacopeias and ethnobotanical treatises and thus its value as potentially proprietary "know-how" is by and large negated since it would be categorized as "prior art." Usually, practitioners applying these phytotherapies are formally trained 


\section{Elvin-Lewis - Evolving Concepts Related to Achieving Benefit Sharing for Custodians of Traditional Knowledge}

in apprenticeships or are required to conform to forms of circumscribed instruction specified by herbalist guilds, institutes of traditional Asian medicines, or colleges of naturopathy and homeopathy, etc. The basis of their curricula is usually derived from published traditional pharmacopeias, monographs, and available databases with specifics of diagnosis, treatment and outcome well delineated. Formulatory guidelines may be strictly adhered to or allow for the substitution of alternative taxa when availability is a factor. In Asian remedies, non-organic components may also be added. Usually the "right to practice" these forms of medicine are mandated by national and state policies and laws. Since current scientific evaluations and well-designed clinical trials are proving the relative worth of many of these treatments, it is likely that many remedies will become popularized outside of the realm of their origins (Elvin-Lewis 2005).

Many of the plants known to these types of traditional medicinal practices are already being incorporated into patented formulas, usually representing a number of taxa, sometimes with other ingredients or even pharmaceuticals; others may simply represent compounds or their derivatives derived from medicinal plants. Patented polyherbals may closely follow known traditional formulatory guidelines (or nuances thereof) or represent an admixture of plant and other substances derived from disparate sources. In the latter instance, these novel formulations of NeoWestern and NeoEastern herbalism have rarely been authenticated for either safety or efficacy (Elvin-Lewis 2005).

Usually it is recognized that TK as modified and applied in a "technological context" is more likely to be subject to patent rights. Generally, to satisfy the novelty criteria required for patenting, evidence must be provided that combining known knowledge has been done in a unique manner. Such a patent does not cover either component individually and use of one of these components will not infringe on the patent covering its use in combination (Hansen \& VanFleet 2003). Currently, Asian pharmacopeias (e.g., Indian, Chinese) are being transcribed into WHO (World Health Organization) and WIPO (World Intellectual Property Organization) Asian databases for general use (Elvin-Lewis 2005). Since these formulations and practices are more rigidly adhered to and may be applied in much the same manner today as they were centuries ago, challenges to the validity of some recently issued Asian or American patents (e.g., uses of curcumin from turmeric US patent $5,401,504$ ) are likely to take place. In the case of turmeric, the patent submitted by two U.S.-based Indians was reversed by the US Patent Technology Office when evidence was brought forward by the Indian Council for Scientific Research (CSIR) that the claims were obvious and anticipated, were cited in numerous references cited in Sanskrit, Urdu and Hindi, and as such its uses had been known as "prior art" for centuries. Patenting the use of a plant part (e.g., root, bark, sap) which is well known for a particular healing or other purpose would also fall under this category and be disallowed. It is noteworthy that in spite of attempts to curtail this practice, patent applications based on well known formulations and uses still occur in many Asian countries. How these conflicts of ambivalence are likely to be viewed by regional patent examiners considering novelty, or are defensible if patenting is conferred, remains to be seen. In contrast, should a particular healing compound/s or its derivatives be derived from the specific plant part, their patenting would generally be allowed since the identity of these substances was "not obvious" in the traditional sense and thus is a patentable invention attained through technical manipulations.

Within this context there has been confusion (McManis 1998) about "the rights of national ownership" when the origins of native taxa are, in fact, unknown because the histories of worldwide distribution have been lost in antiquity, and patents have evolved around chemical processes of extraction and/or stabilization of bioreactive compounds, e.g., azadirachtin from the Indian neem tree (Azadiractha indica A. Juss.) (McManis, 1998), or the serendipitous discovery of new uses, e.g., anticancer pharmaceuticals (vincristine and vinblastine) from the Madagascar, rosy periwinkle (Catharanthus rosea) (Lewis \& Elvin-Lewis 2003). Alternately, many patents derived from Western herbalism have in the past been unchallenged since these usually represent novel mixtures of medicinal plants well known to phytotherapists, or as pharmaceutical compounds were evolved from indigenous pharmacopeias when advocacy for benefit sharing to custodians of this TK were lacking. Most have been derived from the vast amount of secondary data from centuries old pharmacopeias of Europe, Greek and Arabic medicines and academic treatises published primarily in the 19th and 20th centuries on African and North American indigenous pharmacopeias.

Noteworthy examples derived from indigenous sources of the Americas include the Midwestern Amerindian medicinal herb Echinacea, promoted by American eclectic physicians of the 19th century, which has found its way into numerous formulations and polyherbal mixtures in the ever-expanding world of global herbalism. Similarly, 19th century Midwestern physicians adopted the Penobscot use of Podophyllum spp. (May apple) resin to treat venereal warts. Its active but toxic podophyllotoxins were semisynthesized to form teniposide and etoposide which are today topisomerase inhibitors useful in the treatment of lymphoma, leukemia, and brain and bladder cancers. Valuable pharmaceuticals have also been derived from knowledge of indigenous groups living in Peru and Ecuador. For example, during the early 17 th century Spanish colonial period, the value of Cinchona bark as a malaria remedy quickly spread to Europe and elsewhere. Eventually the isolation of the bioreactive alkaloids quinine and quinidine in the 1830s lead to the development of numerous synthetic quinoline compounds that continue to be 
the mainstay of malaria therapy and to treat arrhythmias today. Observation of the muscle relaxant properties of blowgun poisons used by the Jivaro in the 1930s led, in the 1950s, to the isolation of tubocurarine from Chondrodendron tomentosum Ruíz \& Pavón and Curarea toxifera (Wedd.) Barneby \& Krukoff. This compound, derived from native sources, was used as a surgical muscle relaxant until replaced by the synthetic molecules atracurium and vercuronium later in the 20th century (Lewis \& Elvin-Lewis 2003). Over the years the worth of these discoveries, and others, continues to be amplified. As was the custom of the day, none of the custodians of these types of valuable "know how" were ever compensated for the billions of dollars these inventions generated. Only recently has the concept of providing benefits to the custodians of traditional knowledge and the nations, which have provided the genetic resources, emerged. Today, such activities would be considered to be inappropriate, and tantamount to what is called "biopiracy" (exploitive practices by commercial entities in developed countries who profit from the misappropriation of genetic resources or TK from developing countries without returning appropriate benefits to these nations and those of its peoples that provided the TK) (Gollin 1999, 2003, Hansen \& VanFleet 2003). Some countries have become quite proactive in protecting their natural resources and traditional knowledge from these activities. For example, the Peruvian law \#28216, enacted in 2004, charges a commission to create a list of Peru's biological resources (especially in regards to unique taxa) and to draft laws to protect the country from "biopiracy." As a part of its mandate, they will review patents granted locally and internationally and undertake actions to have these revoked should they not comply with current national laws (Anonymous 2004b).

These examples also indicate that realizing the worth of any traditional remedy is not easy to estimate and can be a long and expensive process, with added value being provided by the intellectual contributions of many scientists whose work is supported by private, educational, government or commercial sources. Involved in these endeavors are ethnobotanists who work with the TK holders in collecting the utility-linked information of the plants involved as well as conducting appropriate dereplications to understand how this discovery relates to others already known; botanists that identify the plant or plants in the remedy, their distributions, availability and resource renewable impact issues; epidemiologists and physicians who evaluate their relative value in the context of use; natural products chemists that work with biologists to isolate the bioreactive components, and by appropriate chemical dereplications to affirm their novelty or ubiquity in order to expand their potential uses; and organic and medicinal chemists that may be involved in characterizing and standardizing its formulation as well as developing semi-synthetic or synthetic derivatives that may be more functionally optimal or economical. The costs of conducting the final phases of evaluation for commercial viability are per- haps the most difficult to estimate at the onset of the initial discovery. The multitudes of toxicology tests and clinical evaluations (Phase 1-4) required proving safety, parameters of use, and efficacy can run into millions of dollars.

Therefore, the expenditure of bringing a pharmaceutical to market can be astronomical. Deriving the appropriate formulae for fair benefit sharing to accommodate the "unknowable" value that is added along the way is a challenging process. This is because there is a tendency for pharmaceutical companies to factor in their losses associated with research and development along with their gains. As late as the 1990s the vast majority of companies were not employing utility-linked knowledge to help identify plants and their compounds of worth. Because of this broad-screening approach, which evaluated a wide range of taxa often with specialized mechanistic screens, the "hit rate" was less than $5 \%$ and those bioreactive compounds which were identified were frequently incompatible for human use (Elvin-Lewis 2006). In their search for a potent, unique phytochemical that was readily synthesized, they deemed as unsuitable for development any bioreactive compound that was complex, ubiquitous or moderate in activity. Because of this approach, they rationalized that the low royalty rates they proffered, from any compounds of promise, were justified on the basis of their investment and the meager returns they were likely to get (Vogel 1995, 1996). Unfortunately, those that chose to deprecate bioprospecting activities frequently failed to appreciate these widespread practices.

Vogel (1996) has suggested that "countries that supply biological samples should fix a royalty rate and distribute economic rents and countries which demand biological samples should respect the cartel". Application of this concept, based upon the suggested royalty rate of $15 \%$, may be appropriate to any net (not gross) revenue generated from the sale of a unique botanical but would be currently considered unrealistic and excessive if pharmaceutical research and development is required to develop a commercial product. While evolution of a reasonable formula to insure fair benefit sharing between all parties should always be the final goal in assessing a realistic royalty rate derived from TK-linked genetic resources, a distinction must be made between commercial products that require little, if any development (e.g., botanicals) and those where considerable value is added (e.g., phytopharmaceuticals) to make derived products saleable items.

Many companies also steered away from evaluating extant unknown pharmacopeias because of uncertain policies related to benefit sharing and the costly, time consuming, and frustrating process of evolving agreements with indigenous groups and their host nations. While some Non Government Organizations (NGOs) involved in this process worked diligently to represent the best interests of their clients, and were respected for their efforts, others were not as like-minded. There was always the risk 


\section{Elvin-Lewis - Evolving Concepts Related to Achieving Benefit Sharing for Custodians of Traditional Knowledge}

of intermeddling by certain NGOs that could choose to disagree with all or parts of the agreements and destabilize the negotiations through their advocacy, lobbying, and publicity raising activities. Eventually most companies disbanded phytochemical discovery programs as being unprofitable. This was a frustrating time for ethnobotanists, other scientists, and TK holders alike who were hoping that the information and specimens they were providing would be appropriately assessed to optimize their potentials.

Today, as more and more discoveries are being made and the herbal and functional food industry expands, there is a growing realization that medicinal plants can be the source of valuable phytopharmaceuticals or even pharmaceuticals. Often using utility-linked knowledge as a guide and appropriately linked bioassays, bioreactive plant compounds can be readily identified at significantly higher hit rates $(>70 \%)$ and determined if they are suitable candidates for commercial development. In this way, plant products standardized for their bioreactive contents may be sold as phytopharmaceuticals. These may contain one or more compounds deemed too complex for pharmaceutical development but are nonetheless recognized as being useful as found in their natural state. As technologies have advanced, compounds from medicinal plants once deemed as too moderate in activity or toxic for human use are being modified to amplify their efficacy and safety profiles. With a better understanding of these examples and the recognition that the literature is replete with instances where medicinal plants have provided worthwhile pharmaceutical leads, new interest is evolving based on utility linked knowledge (Elvin-Lewis 2005, 2006, Lewis \& ElvinLewis 2003, Lewis et al. 2004).

\section{Protecting Circumscribed Traditional Knowledge}

The ability to utilize for profit information that is readily available and in the public domain is fundamentally different from issues related to circumscribed TK. Unfortunately, many researchers are unaware of how to handle this type of potentially proprietary information and are naïve regarding its value towards the creation of "utility patents" or as a basis of access and use fees which can be used to compensate, in part, the time and effort of their informant/collaborators (Lewis et al. 1999). Unless mandated by national sui generis policies, there is still a tendency by many ethnobotanists and the like, to acquire this type of information in informally evolved ways which may or may not include identifying the informants, formalizing with them documents of "prior informed consent" (PIC), or evolving fair and up front compensation to the contributors of the TK. These methods may avoid the additional steps of providing the participants with the purpose of the project and having them signify in some appropriate manner their acquiescence to providing the information. According to Hansen \& VanFleet (2003), while there is not any legal obligation to elicit PIC in countries that are not signatures to the CBD there is a growing consensus that it is wise to do so not only for professional or ethical reasons but also to avoid future challenge or criticism.

Eliciting PIC may involve all community members, their representatives, or only certain individuals willing to participate in the project. It implies that "in all situations where an indigenous people or local community is involved in a transaction encompassing intellectual property rights, biological resources, or TK, there will be full consultation, and complete exchange of information, leading to full and explicit consent prior to any appropriation of information" (Chennels 2003). Depending upon the literacy level of the collaborators/participants this affirmation may constitute the use of fingerprints, name symbols, or signatures adjacent to their name, and may also include some type of acknowledgement (e.g., official stamp) from community and clan and/or tribal officials that they sanctify such work. Within the context of the ICBG-Peru project these documents were called "actas" and were elicited in each participating community (Lewis 2000, Lewis \& Ramani 2003, In Press). Under the Bonn Guidelines (Anonymous 2002), a community has the option of not participating.

According to statements of the WIPO (World Intellectual Property Organization) and WHO (World Health Organization), PIC should be a necessary requisite whenever any proposed patent is derived from the information. In fact, several European countries, such as Denmark, Norway, Germany and Romania, have already implemented or are currently discussing legislative proposals in respect of disclosure requirement pertaining to (among others) PIC (Koopman 2006). While the evolution of legally binding biological collecting and know-how licensing agreements are ideal, particularly when collections of data and plants are being made to analyze the worth of an indigenous pharmacopeia, these activities are expensive and time-consuming to evolve. All parties must be legally represented for the agreements to be appropriately binding. In this regard, perceptions regarding how TK holders should be represented have radically changed as educational levels have risen and communities are becoming aware that they are deserving of benefits. Forms of trusteeships are becoming outmoded as more and more indigenous groups are acquiring national recognition as juridical bodies. This status allows them to negotiate, with appropriate legal representation, on their own behalves. Within the context of these accords, forms of oversight need to be instituted to assure that issues related to the protection of potentially proprietary information and compensatory arrangements are being appropriately managed. Within the perspective of the ICBG-Peru project, for example, these efforts assured that the informants/collaborators not only received forms of up-front compensation for their involvement with the project, but also were also aware what long-term benefits may evolve (Lewis 2000, 
Lewis \& Ramani 2003, In Press). With the recognition that there is a need for intellectual property-related legal assistance in developing countries, and their public interest clients (Gollin 2003), several educational institutions, such as the recent Intellectual Property and Business Formation Legal Clinic created at Washington University School of Law, and others, are beginning to provide pro-bono publico (for the public good) services to their communities and elsewhere.

In spite of all attempts to conduct these types of negotiations appropriately and efforts to comply with national, regional pacts, and international treaties, there will always be misinformed groups and "watch dog" organizations that will try to sabotage these efforts. The rationale for doing this is as varied as the personnel that make up these groups, the types of information that they have accumulated, and how they use it. Much dissent is based on the lack of knowledge of the contents of the agreements or their disagreement with how they were evolved. Within this context, few that wish to derail the process understand laws which have been evolved to protect proprietary knowledge (e.g., patent law) or how these laws can be used to benefit all those that contribute to the evolution of a viable commercial product. Others may simply disagree with the concept that patenting is appropriate and would prefer to see TK available for the "common good."

Unfortunately, many researchers are still likely to disseminate potentially proprietary TK in publications (grants, papers, dissertations, brochures, herbarium annotations, web-sites, the Internet, etc.) and verbal presentations and by doing so cause it to be considered CK and negate it's worth as proprietary know-how. Also, these types of disclosures are likely to render the information as unpatentable since in US patent law it would be considered "prior art," particularly if the invention or discovery appears in a printed publication in either the US or foreign country more than one year before a patent's filing date or is dated before the act of invention or conception (Hansen \& VanFleet 2003). Also, according to US patent law, the appropriation of much foreign information, including information orally transmitted (and uncodified TK), can occur since only foreign written information is assessed for novelty during patent review of an invention. The relevant sections of the US patent statute S102 regarding conditions for patentability, novelty and loss of right to patent are as follows: "the invention was known or used by others in this country, or patented or described in a printed publication in this or a foreign country, before the invention thereof by the applicant for patent" or "the invention was patented or described in a printed publication in this or a foreign country or in public use or on sale in this country, more than one year prior to the date of the application for patent in the United States" (www.bitlaw.com/source/ 35usc/102.html). European patent law is not so exclusive and considers that everything which does not belong to the state of the art is novel. The state of the art is broadly defined as anything which has been made available to the public in whatever form (oral, written, by use, and so forth), at any time, in any country around the world. In principle this absolute novelty standard should prevent the appropriation of TK in the public domain through patent law. Closely related inventions would lack novelty under European standards. This law implies that any type of traditional knowledge that is orally transmitted or publicly known through demonstrated and public use would fall into this category. Information regarding European patent law can be obtained through www.european-patent-office.org (Koopman 2006). The patents in respect of compounds derived from azadirachtin are illustrative: the European Patent Office has revoked European Patent EP 436257B1 on a "novel insecticide and...fungicide derived from a neem seed..." for lack of novelty in light of prior use and communications hereon in India. The revocation was upheld on March 8, 2005, and the appeal against it dismissed (Koopman 2005b). In time this approach may also apply to how TK is viewed in the US patenting process. Currently this fundamental difference impacts on how traditional knowledge is likely to be applied and is possibly the root of much dissention when these differences are not understood.

Whether advertent or otherwise, these types of disclosures nullify the capacity for the creators and holders of traditional knowledge to pursue intellectual property protections. For exposure to have a negative impact on a patent application, patent examiners must easily locate and rely on the accuracy of any prior art information (e.g., an appropriately designed electronic TK database). In certain cases such a defensive disclosure may remain anonymous so as not to attract unwelcome attention to an individual or community. When the prior art has been missed in the examination process, challenges to overthrow an existing patent are not readily achieved and are often too costly to be worthwhile (Hansen \& VanFleet 2003). Nevertheless, the aforementioned example of the opposition against and revocation of the "European Neem Patent" shows that this need not be the case.

Appropriate oversight and management of these types of data are never easy, particularly among academics where the requirement to "publish or perish" is the driving force for professional survival and the need to protect these types of data is poorly understood. Unfortunately, many professional organizations and journals that give lip service to protecting TK still do little to prevent this unwarranted dissemination at meetings and through their publications. Under these circumstances it would be beneficial if guidelines were available so that presenters and authors would know from the onset what is ethically acceptable and when public disclosure is not. Should indemnification be required by the journal or professional sponsor to assure that appropriate guidelines are being followed, it would place the burden of ethical behavior on those pre- 


\section{Elvin-Lewis - Evolving Concepts Related to Achieving Benefit Sharing for Custodians of Traditional Knowledge}

senting the information and not on those sponsoring its distribution.

To prevent improper revelation of the specific whereabouts of taxa linked to valuable TK, only minimal data should be cited. A disclaimer could be added to the label stating that to protect the best interests of the collaborating TK holders the investigators have withheld ethnomedical or geopositioning information. This allows for appropriate systematic evaluations to proceed without compromising either the value of the information or location of specific plant populations. To do otherwise could lead to the extirpation of valuable specimens and/or rare plants.

Care must also be taken to protect the identity of specimens undergoing screening for bioreactivity and chemical evaluations. Coding of these samples should not refer to the collection number but to another system of specimen identification devised especially for the purpose of keeping this linkage sequestered. This is a useful ploy especially if the specimens are being sent to several collaborating laboratories and if the data that are generated are used for publications and presentations. Once appropriate studies have been completed, including both ethnobotanical and chemical dereplications and it becomes apparent that the knowledge is already well known, it may be appropriate to reveal the identity of certain specimens and their bioreactive compounds. These types of data are useful to researchers since they can serve to identify the commonality of certain valuable medicinal plants without compromising the identity and worth of those that are exclusive to a particular group. Within this context such comparative treatises need not reveal unique nuances of preparation or combinations in formulations which might also confer value (Lewis et al. 2000).

As will be discussed below, in some countries, public policy and laws already mandate various forms of protection for holders of TK. For example, Peru recognizes that certain indigenous pharmacopeias were already published before their current law (8/10/2002 -\#27811) protecting traditional knowledge was established. To accommodate this, Peru has evolved a graded scale of how remuneration can be elicited. This is based upon the time of its release of up to 20 years preceding creation of the law and a standard rate thereafter. Considered as $\mathrm{CK}$, a portion of this revenue generated from commercialization is to be allocated to a fund designated to promote the welfare of indigenous people. In this context it is unclear if the originators of this knowledge would be the recipients of any preferential benefits.

Data that are restricted to a particular group of individuals as "know how" are particularly valuable and must be carefully safeguarded. This is particularly challenging to investigators who require support to continue to evaluate the worth of this information so that the goal of reaching optimal benefits for TK holders can be reached. Treat- ing TK as "know how" is a recent innovation (Lewis et al. 2000) and few granting agencies and their reviewers fully understand the need to present this information in a form which will neither jeopardize its worth nor affect any fiduciary restrictions which have been evolved between the investigators and TK holders. These obligations can limit the nature of information that can appear on grant applications in that the identity of plants or their compounds may only be able to appear in coded form. This necessity is in effect a "catch 22" in that certain reviewers, who are often under confidentiality constraints of the granting agencies themselves, do not always understand why this further restriction is necessary until patenting is achieved. There is a real risk that certain reviewers presented with this implicit information may so dislike this approach that they do not take time to read the details of the proposal and the gross misinterpretations that result can adversely affect funding possibilities. Also, the process of distribution and review does not necessary insure that information is appropriately safeguarded for tracing any inadvertent dissemination. This is particularly true for the U.S. National Institute of Health and other government review panels which can be large and made up of scientists from a cross section of academia and industry. Moreover, after funding, these grants are essentially in the public domain, and although there is some leeway in allowing only redacted copies to be distributed, there is always a concern that this approach lacks the necessary safeguards to prevent inadvertent dissemination of sensitive data. Private foundations and industrial partners, sympathetic to these restraints, may be the few alternate resources available.

In the evolution of protective mechanisms, there are qualified uses of TK that must be considered either through customary use or agreements that are evolved between interested parties. There is a need to establish confidentiality or non-disclosure agreements to protect potentially proprietary knowledge; to define how licensing arrangements may evolve to either transfer to rights to an outside party as in an exclusive license, to allow the TK holders to maintain their rights through a sole licensing arrangement or with a non exclusive license. Outside contractors undertaking bioprospecting should be aware that it is not always easy to identify all members of a group who may lay claim to specified TK or, for that matter, to evoke full consensus from all concerned. There is always a risk that those initially ignored or unidentified during the contractual process, or recalcitrant members of a group, may have second thoughts once data and specimen collection are taking place and benefits are being realized (e.g., Kraho Indians of Brazil) (Hansen \& VanFleet 2003). While the task of satisfying all concerned parties is likely to be challenging, and avoiding litigation not always possible, finding ways to rationally overcome these issues between the contracting parties and others in dissent is a logical solution so that appropriate evaluations can proceed. The goal should be to evolve a win-win situation rather than one where no one benefits. Customary law might be applied to answer- 
ing some of these questions and ultimately depends upon the legal status of the TK holders and how national laws govern these types of interactions. Generally, the notion of legal centralism stands in the way of complete recognition and enforcement of customary laws in states. However, the acknowledgement of indigenous land rights that has occurred in different fashion in a variety of countries (including the Philippines, Australia and Brazil) may provide inspiration to identifying the legal tools to create a situation that is beneficial to all (Koopman 2005b).

Changes in attitudes regarding these types of activities began to evolve in a substantial way in the early 1990s when professional societies (Table 2) and international legal institutions recognized that major changes would have to be made as holders of traditional knowledge became aware of their worth (Table 3). Noteworthy have been policies derived from International Organizations such as the CBD, (Table 1), the UN (UN 1994), WHO, activities of WTO, the World Intellectual Property Organization (WIPO), and all their efforts to define and influence how these activities can be ethically, optimally and legally achieved through evolving laws and treaties. In South America, in particular, these guidelines to protect TK have also been followed by the evolution of certain regional laws encompassing a number of nations (e.g., Andean Community of Nations: Communidad Andina de Naciones or CAN), in addition to specific national laws (e.g., Peru, Venezuela, Brazil). In

Table 2. Ethical Guidelines.

\begin{tabular}{|c|c|c|}
\hline Year & Convening Organizations & Ethical Guidelines \\
\hline 1988 & Society for Ethnobiology & The Declaration of Belem. \\
\hline 1988 & $\begin{array}{l}\text { World Health Organization } \\
\text { International Union for the Conservation of Nature } \\
\text { World Wild Life Fund }\end{array}$ & $\begin{array}{l}\text { Chiang Mai Declaration for Conservation of Medici- } \\
\text { nal Plants. }\end{array}$ \\
\hline 1990 & Botany 2000 Herbarium Curation Workshop & $\begin{array}{l}\text { Code of Ethics for Foreign Collectors of Biological } \\
\text { Samples. }\end{array}$ \\
\hline 1990 & World Archaeological Congress & $\begin{array}{l}\text { Code of Ethics on Obligations to Indigenous Peo- } \\
\text { ples. }\end{array}$ \\
\hline 1991 & Society for Economic Botany & $\begin{array}{l}\text { Professional Ethics on Obligations to Indigenous } \\
\text { Peoples. }\end{array}$ \\
\hline 1992 & $\begin{array}{l}\text { National Institutes of Health \& National Cancer Insti- } \\
\text { tute (USA) }\end{array}$ & $\begin{array}{l}\text { Conclusion of a Workshop on Drug Development, Bi- } \\
\text { ological Diversity and Economic Growth. }\end{array}$ \\
\hline 1992 & $\begin{array}{l}\text { World Resources Institute } \\
\text { International Union for the Conservation of Nature } \\
\text { United Nations Environment Program }\end{array}$ & Global Biodiversity Strategy. \\
\hline 1992 & American Society of Pharmacognosy & Williamsburg Declaration. \\
\hline 1992 & $\begin{array}{l}\text { UNESCO Seminary on the Chemistry of the Rainfor- } \\
\text { est Plants }\end{array}$ & The Bukittingii Declaration. \\
\hline 1992 & $\begin{array}{l}\text { Seventh Asian Symposium on Medicinal Plants, } \\
\text { Spices and Other Natural Products }\end{array}$ & Manila Declaration. \\
\hline 1993 & $\begin{array}{l}\text { World Wild Life Fund, UNESCO, Royal Botanic Gar- } \\
\text { den (Kew) }\end{array}$ & $\begin{array}{l}\text { Guidelines for Equitable Partnerships in New Natu- } \\
\text { ral Products Development of the People and Plants } \\
\text { Initiative. }\end{array}$ \\
\hline
\end{tabular}

the pan-Pacific area, the Auckland Declaration will be the basis for similarly conceived laws (Anomymous 2004a).

\section{Defining ownership of TK}

Defining parameters of TK ownership is dependent upon the legal interpretation of current laws and policies. It is an evolving process with the goal of developing international mechanisms to ensure the protection of traditional knowledge and folklore, as well as protecting genetic resources (WIPO 2005b). In the context of growing global needs against misappropriation and misuse, member states of the WIPO continue to address these issues through the Intergovernmental committee on Intellectual Property and Genetic Resources, Traditional Knowledge and Folklore (IGC) (WHO 2004a, WIP0 2005b). The United Nations draft declaration on indigenous rights, Article 29 states: "indigenous peoples are entitled to the recognition of the full ownership, control and protection of their cultural and intellectual property. They have the right to special measures to control, develop and protect their sciences, technologies and cultural manifestations, including human and the properties of fauna and flora, oral traditions, literatures, designs and visual performing arts" (Anomymous 1994, Hansen \& VanFleet 2003, UN 1994). This declaration and the related initiatives may perhaps be based on a variety of (international) public law instruments includother genetic resources, seeds, medicines, knowledge of 


\section{Elvin-Lewis - Evolving Concepts Related to Achieving Benefit Sharing for Custodians of Traditional Knowledge}

Table 3. Intellectual Property Rights.

\begin{tabular}{|c|c|}
\hline Year & Intellectual Property Rights \\
\hline 1883-1967 & World Intellectual Property Organization (WIPO) \\
\hline 1945 & Agriculture Organization of the United Nations (FAO) \\
\hline $1961-1991$ & International Union of New Varieties of Plants Convention (UPOV) \\
\hline 1992 & Convention of Biological Diversity and ad hoc group on Traditional Knowledge \\
\hline 1994 & General Agreement on Tariffs and Trade (GATT) \\
\hline 1999 & WIPO: Recognition of Traditional Knowledge and IP protection \\
\hline 2000 & United Nations Conference on Trade and Development (UNCTAD) \\
\hline 2001 & $\begin{array}{l}\text { World Trade Organization (WTO), Trade Related Aspects of Intellectual Property Rights (TRIPS) Coun- } \\
\text { cil }\end{array}$ \\
\hline 1999,2000 & WIPO Fact Finding Mission to Peru, 1999 vs. a vs. ICBG-Peru agreements; published 2000 \\
\hline 2002 & $\begin{array}{l}\text { Regional Pacts: e.g., Andean Community of WTO (Bolivia, Colombia, Ecuador, Peru and Venezuela) } \\
\text { IP Law }\end{array}$ \\
\hline 2001,2002 & National Laws: e.g., South America - Brazil 2001; Peru 2002 \\
\hline 2004 & Auckland Declaration \\
\hline
\end{tabular}

ing, of course, the $\mathrm{CBC}$ and those pertaining to human rights, which are arguably more important and far reaching (Koopman 2005b). Currently, variations on this intent occur worldwide, however, there are limitations to the scope of legal directives, which may, for example, involve solely the protection of biological and genetic resources, to specific kinds of traditional knowledge, such as customary herbal medicine, images in handicrafts (Panama), to honoring cultural or spiritual sensitivities (e.g., New Zealand, Canada) (Havemann 1999). For example, title of TK may be claimed by the state, as it is in Madagascar and Viet Nam, in nations of Amazonia, India, and South Africa, considered the possession of indigenous groups or tribes, or in Tanzania, ascribed to specific healers. In Africa as a whole, appropriate management of TK related to genetic resources is still an evolving process. As was evident at the eighth session of the WIPO Intergovernmental Committee on Intellectual Property and Genetic Resources, agreement on many fundamental issues associated with protection, disclosure, evidence of prior informed consent, access, and benefit sharing has yet to be achieved (WIPO 2005b).

Variations are also apparent in the Western Hemisphere in that Brazilian law does not require documentation or registration of TK but mandates that TK holders must authorize its transfer, licensing and assignment. Furthermore, the Brazilian Management Council requires that these origins be cited before access to genetic material is allowed. These mechanisms provide ways in which recipients of any potential benefits are identified. This law covers both TK known to indigenous groups as well as those derived following colonization (e.g., African-Brazilian origin). Costa Rican law regulates access and covers all intangible components whether it's traditional or not, individual or collective, including knowledge related to genetic or biochemical components. Alternately, Sui generis laws linked to biodiversity are narrowly defined in Peru (Law 28216), which restrict patents on its biological resources. There, concerns are primarily focused on patented botanicals that are sold elsewhere which utilize native Peruvian species obtained illegally, or because they involve the unauthorized use, without compensation, of traditional knowledge (Anonymous 2004b, WIP0 2005b).

\section{Challenges to Protecting Commercially Viable TK}

While needs to evolve appropriate benefit-sharing mechanisms are currently recognized, and definitive guidelines and laws are evolving, it will take the "test of time" to see how these are practically and fairly applied. Depending upon the country, ultimate protection of any concept with commercial potential can be conferred through trade secrets, petty patents, and patents. In many Amazonian countries, national laws, regional pacts, and international treaties now affirm the right to indigenous ownership of their traditional knowledge. There, examples exist of distinctive knowledge that is attributed to a particular population associated with a tribe or clan, speaking a unique language, which has historically resided in a circumscribed territory with limited interchange with other groups. Much of this information is not in the public domain. However, when indigenous groups claiming affiliation to one tribe reside in a number of neighboring countries, such as the San of Africa (Chennels 2003) or the Maya of Central America, challenges to establish ownership and appropriate benefit sharing may be insurmountable unless all nations involved within the traditional tribal territory are in agreement as to how this may be achieved. Less clear as to whom the beneficiaries may be are people linked together with a common language, but not necessarily by historical tribal affiliation, ethnic or national origin such 
as the Quichua speaking inhabitants of the Andes. Their pharmacopeia having evolved uniquely since colonization represents the collective traditional knowledge of many types of people. Therefore, should a new commercial entity arise, some sort of regional benefit sharing might logically be the answer to the complex problem of identifying one or more suitable groups of beneficiaries.

\section{Trade secrets and know how}

It is appreciated that even indigenous TK is usually communally and not exclusively held and there is always the risk of information being lost through advertent or inadvertent disclosure. However, the natural evolution of TK suggests that this knowledge may only have value in a temporal context. As time passes, there is always the risk of this information being independently discovered, "adulterated", or lost because of lack of need or skill levels to apply it. From a Western perspective, how many of us know, use, or apply useful knowledge considered as "old wives tales", our grandmother's, or great grandmother's generation once valued?

Nonetheless, evolving international law acknowledges that there is a need to protect TK from unauthorized access, commercial use, third party claims, inappropriate cultural use, or misleading or deceptive practices. Many ways of protecting TK such as trade secrets or exclusive "know how" to prevent nefarious exploitive activities must be evolved when using potentially proprietary TK. As a trade secret this knowledge can be kept secret indefinitely, however, this method is vulnerable, to; independent discovery, accidental or actual disclosure, or, in the case of certain phytochemicals, reverse-engineering. According to Koopman (2006), keeping TK secrets may be a way to prevent appropriation of the knowledge pursuant to US patent law but it will facilitate and ease appropriation thereof by inventors that apply for European patents (i.e., given the absolute novelty standard applied under European patent law, all TK that been openly communicated in whatever way, becomes part of the art, which is thus not the case with TK that is held secret). Also, keeping knowledge entirely and/or rigidly secret may not be the most efficient manner of pursuing exploitation and, therefore, benefit sharing. Alternately, this information may be licensed for use. For example, a form of licensing agreement was evolved between a Peruvian indigenous group and an American pharmaceutical company which utilized their specific proprietary "know how" during the evaluation of their medicinal plants for pharmaceutical potential. During a specified period these know-how licensing fees provided upfront remuneration to the communities involved and aided in many capacity building ventures (Lewis 2000, Lewis \& Ramani 2003, In Press).

\section{Trademarks}

Among current methods of protection, trademarks are being used widely to identify traditional originators. Unlike forms of patenting it is an inexpensive way to protect the identity of the knowledge holder through an indication mark, not the knowledge itself. Appropriate contractual arrangements can be made with those wishing to undertake profitable ventures so that benefit sharing is ensured. Examples of this nature are medicinal balms which are sold in Viet Nam and the Russian Federation. In contrast, while certain North American First Nation or Indian tribes have evolved trademark protection regarding their art, this method has not been extended to uses of their medicinal plants, presumably because other types of healing rituals are considered a necessary component of the process (e.g., use of energy medicine such as repetitive mantras) (Havemann 1999).

\section{Petty Patents}

Petty patents (Table 4) are another, less-expensive mechanism which has been evolved in some countries to protect TK (Table 5). It is an ideal way to protect circumscribed botanical formulations for a limited period of time and provides the needed monopoly from 4-10 years when their marketing value is being established. In legal terms, a lower standard of inventiveness can be applied, however, the claims must define the invention as having an "innovative step" which is a substantial contribution to the art, yet it need not be non-obvious. These claims are registered and examination is only required prior to enforcement. Currently there are no international agreements to facilitate these types of applications and only a few thousand are registered each year.

\section{Patents}

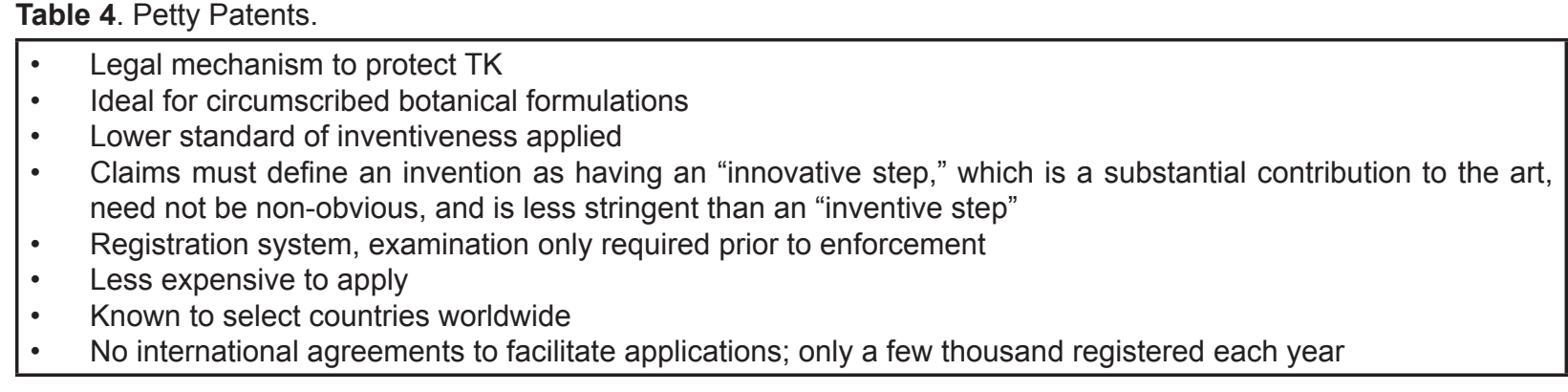




\section{Elvin-Lewis - Evolving Concepts Related to Achieving Benefit Sharing for Custodians of Traditional Knowledge}

Table 5. Countries were Petty Patents Exist.

\begin{tabular}{|l|l|}
\hline AFRICA & $\begin{array}{l}\text { Ethiopia, Kenya, Organisation Africaine de la Propriété Intellectuelle (Republics of Camer- } \\
\text { oon, Central Africa, Chad, Congo, Dahomey, d'Ivoire, Gabon, Malagasy, Mauritania, Niger, } \\
\text { Senegal, Upper Volta). }\end{array}$ \\
\hline CARIBBEAN & Trinidad \& Tobago \\
\hline CENTRAL AMERICA & Costa Rica, Guatemala, Mexico \\
\hline CENTRAL ASIA & Kazakhstan, Kyrgyzstan, Tajikistan, Uzbekistan \\
\hline EAST ASIA & China, Japan, Korea, Malaysia, Philippines, Thailand \\
\hline EUROPE & $\begin{array}{l}\text { Austria, Belarus, Belgium, Bulgaria, Czech Republic, Denmark, Estonia, Finland, France, } \\
\text { Georgia, Germany, Greece, Hungary, Ireland, Italy, Montenegro, Netherlands, Poland, Portu- } \\
\text { gal, Republic of Moldova, Russian Federation, Serbia, Slovakia, Spain, Turkey, Ukraine }\end{array}$ \\
\hline OCEANIA & Australia (now redefined as “Innovation" Patents) \\
\hline SOUTH AMERICA & Argentina, Brazil, Colombia, Peru, Uruguay \\
\hline SOUTHWEST ASIA & Armenia \\
\hline
\end{tabular}

Distinctions between a patentable invention and an unpatentable discovery are frequently debated (Koopman 2005a) and there is a growing consensus that reformulation of current patent laws are needed to accommodate these challenges, particularly as it related to the utilization of biotechnological inventions that involve TK (Sherman \& Bentley 1999). While nuances of patent law may differ from one country to another, in general terms it is a legal certificate that authorizes its holder to exclude others from commercially using the underlying inventions. The certificate can be granted for products as such, the uses thereof, and processes. Different requirements, such as pertaining to the novelty and non-obviousness of the invention, must be met before the certificate could be granted. This is an expensive process not only to initiate but also to provide oversight from untoward encroachment over the 17-20 years of its lifetime. In order to extend the longevity of a certain invention, additional (minor) inventive steps may be taken as to enable acquisition of a new patent for a not so different invention. Some consider this practice to be an example of how the patent system can be abused so as to serve the private interests of the patentees (Koopman 2006). International patents afford the most comprehensive protection (de Carvalho 2003).

To many, the application of a utility patent to any type of TK is an oxymoron, because "inventorship" cannot be ascribed to persons conveying this type of knowledge, or the plant/s that are used. Moreover, there are issues of conveying different types of proprietary rights - thus excluvity - to different resources of research and development and the subsequent conflict of rights that may occur. Changes in the law have been proposed through the TRIPS agreement to accommodate the rights of TK holders sharing community knowledge by specifying its source (Lewis \& Ramani 2003, In Press, Quinn 2001). While some groups may consider this method as being culturally inappropriate, others may welcome this protection as a way to improve their livelihood (Koopman 2005a). Also, issues of dissension frequently occur over a misunderstanding of the process, with concerns erroneously arising over beliefs that restrictions to traditional uses have occurred. An early example, frequently cited as biopiracy, is the 1992 W. R. Grace patent (US 5124349) associated with the process of stabilizing compounds, such as azadirachtin, in Azadarachta indica (neem) seeds and its oil for use as insecticides. According to Robert Larson, President of Vikwood Ltd whose company in 1985 originally invented a similar stabilizing method from neem seed extracts (US 4556562), the controversy was incited by the Indian media and outraged Indian farmers who were encouraged to erroneously believe that patenting would impair their traditional uses of crude neem products for the same purposes. Nothing could have been further from the truth. It took time for this misunderstanding to be resolved. What became clear was that while the bioreactivity of these compounds had already been identified and widely acknowledged, they were unstable in extracted form and thus not commercially viable. The invention claimed in the W.R. Grace patent was related to the process of their stabilization and was unknown to scientists in India and elsewhere. Therefore assertions being perpetrated that the invention was "not new" could not be substantiated within the context of the US relative novelty rule or patent law which allows inventions based on knowledge present in the public domain to be patented. As a result of this invention, similar neem-related patents, generated primarily by Indian scientists, were evolved in the US and elsewhere. With the birth of a new industry and the increased need for raw material, both the owners of the patents and local farmers in India and other countries where plantations of the neem tree grow, have benefited considerably (McManis In Press). Also, confusion to rights to "ownership" of knowledge related to the use of a medicinal plant may arise when others, to affirm the criteria of the discovery being "non-obvious" to a person "skilled in the art," add necessary inventive steps leading to novel discoveries such as identifying and using only the natural bioreactive compound or further developing semi-synthetic or synthetic molecules which have greater marketing potential. 
This, of course, was not the case with azadirachtin from neem, since its value as an insecticide was already well known in India before the European patent on its use was granted and eventually rescinded.

In certain instances linkage to relevant TK may not be cited in the patent, or overlooked by patent examiners who must rely on currently available, but generally ambiguous, databases (Band 1997, Koopman 2005a). Advertent oversights or otherwise, it is not always easy to define the identity of just one nation of origin or all relevant stakeholders, who might be worthy of sharing in the benefits accrued from a patented discovery. This is particularly true when inventions are made from taxa that are cosmopolitan or widespread in distribution (Vogel 1996), when the bioreactive compounds in question can be found in disparate taxa, or where TK linked to the patent is generally known. To be fair, review of released patents to assure that biopiracy has not occurred should be carefully and rationally vetted before accusations of misconduct are made.

To overcome some of these issues when circumscribed TK is used, its "owners" who transmitted this knowledge (under the mandates of prior informed consent) can be cited in the preamble of the patent and apportionment of ownership assigned to an appropriate juridical body representing the indigenous group or groups. This model builds on the existing statutory possibilities of conveyance of patents to multiple inventors (shared inventorship/patents). However, this does not affect the claim to the underlying invention by the patentee - the preamble only has interpretative relevancy. Examples of how this can be achieved will be found in a current patent application now under examination in the U.S. Patent and Trademark Office which involves discoveries made during the PeruICBG project regarding bioreactive compounds found in Aguaruna malaria remedies. This patent recognized the contribution of their know-how to the inventions, names those providing the information, and assigns the ownership to the confederation of indigenous peoples to which they belong as well as to the three collaborating universities that worked towards these discoveries. Benefits accruing from any commercial development would therefore be equally shared between all four entities, with three quarters of the revenue being returned to the host country through its two academic institutions and indigenous participants (Lewis \& Ramani 2003, In Press, McManis 2003). Within the context of understanding between these partners and any future patents that are likely to be generated, issues related to identifying types of commercialization, how and when enforcement will be applied, and who will bear the costs incurred, continue to be matters of mutual discourse.

Evolving these types of utility-based patents rewards those who have amplified this original value linking TK to the discovery of, for example, a useful phytochemical. It provides a mechanism by which "know how" not only has value but in which ownership can be shared between TK holders and those that provided the value-added technology required to reduce these concepts into a potentially viable commercial entities. Therefore ownership and inventorship should not be confused and how benefits are apportioned as related to TK linked patents depends upon how the totality of "inventorship" and "ownership" is assigned to all those involved in the inventive process. In the process of "reducing to practice," added value is likely to evolve in many ways not only by the discovery of the active component/s in the original plant or other taxa, but also if any added uses and formulations are evolved, etc. Within this context there is considerable difference between the investment required to develop a commercial product utilizing raw material, natural products designed to amplify the worth of known phytochemicals (e.g., phytopharmaceuticals), or the development of pharmaceuticals that must overcome hurdles of research, development and regulatory processes, so as to ensure parameters of use, safety, and efficacy. As long as the expectations of all stakeholders are not realistically addressed and satisfied, creating the appropriate compensatory formulae will be subject to challenge.

In contrast to the majority of other countries that establish priority of inventorship based on the "first to file," the US concedes priority to those providing temporal proof of being the "first to invent." In order to provide parity with foreign applicants under the GATT Uruguay Round Agreements and to provide more time to file, the US provisional patent was evolved in 1995 to harmonize these two points of view. This is an invaluable mechanism for university investigators and their students who can utilize this as a means to establish an early filing date and allow the term "patent pending" to be applied in a doctoral dissertation or allied presentation. For academic purposes, this provisional patent is otherwise, non-public, and "filing is permitted without a formal patent claim, oath or declaration, or any information disclosure (prior art) statement " (www. uspppto.gov/web/offices/pac/provapp.html). This low-cost method protects proprietorial traditional knowledge during a critical but short period of time when certain information is being considered as being worthy of undergoing the more prolonged and expensive process of a non-provisional patent application. While many of these provisional patents never realize a non-provisional submission, this non-extendable, 12-month pendency period provides, within this time frame, the opportunity to either convert to a non-provisional patent status or file for this separately. There are advantages to both in that the first way applies the original filing date to the inventive process whereas the latter prolongs the time for up to 12 months in which the non-provisional patent can be extended. Whatever the case, claims in the provisional patent must support the subject matter on the non-provisional patent application. Also, both provisional patents and full patent applications can be categorized as non-public, thereby safe-guarding the dissemination of this information further (Anonymous 1995, Bitlaw 2005, Brown \& Michaels 2005, Ladas \& Perry 2005). 


\section{Elvin-Lewis - Evolving Concepts Related to Achieving Benefit Sharing for Custodians of Traditional Knowledge}

\section{Sui Generis Laws}

Sui generis laws, defining access to indigenous and national TK are evolving so that respect and preservation of this information is assured during the period where aspects for its wider application and means to provide fair and equitable benefit sharing are being explored. Included in these laws can be regulations which acknowledge the need to recognize and protect the rights of peoples who have evolved this TK and any genetic resources that may be associated with its use. There is a growing recognition that these tangible resources must be conserved, used in a sustainable manner, protected, and subject to forms of legal transfer. Furthermore, in order to encourage sustainable development and capacity building and to promote additional expansion and innovativeness within communities of TK holders, appropriate mechanisms of benefit sharing need to be mandated. These would include defining the type of start-up/upfront benefits, milestone payments, and product benefits through royalty payments. Remuneration may be in some form of financial arrangement placed in a trust fund to support community development projects and training, or by providing equipment (e.g., computers/software, solar panels). Capacity building can take many forms from providing better educational and health opportunities for all to encouraging the development of new crops (e.g., medicinal plants) and cottage-based industries related to these activities. Within this context, opportunities to train local parataxonomists and paraethnobotanists to aid in these endeavors may evolve. For example, improving the quality of TK-based products could result in removing low-quality traditional medicines from the marketplace as well as providing a mechanism whereby income is generated from the sale of superior products. While these innovative laws are ethically derived, many require further refinement so that they can be practically executed (Lewis et al. 2000).

Table 6. The Requirement.

\section{The Requirement (as a Proposed Modification of Patent Law)}

There is a proposed change in patent law being considered by WTO member states. Currently, disclosure is required only if necessary to explain the invention or the "best mode" of protecting it. Full disclosure of TK-associated genetic resources, in what is referred to as the "Requirement," is considered as an accessory which relates to the invention cited in the patent collaterally. This involves citing the origin of the genetic resources and providing proof that "prior informed consent" has been elicited from the TK holders of this utility-linked knowledge. According to de Carvahlo (2003) "it is not ancillary to patent law... it is ancillary to administrative and/or contract law." He further believes that non-disclosure of this information would constitute fraud and cause the application be considered an "abuse of rights." To be consistent with the TRIPS Agreement, he further proposes that disclosure of origin and prior informed consent be made a condition of enforcing the patent rather than imposing these requirements as a condition of patentability (de Carvalho 2000). Whether or not this proposal has any material effect, or may violate TRIPS, remains to be ascertained (Koopman 2006). As mentioned previously, several European countries are addressing issues related to the Requirement, with the intent of changing their patent laws accordingly. There is a variation of how this need is perceived, since some countries may not make this a formal condition or restrict it only to patents, or other areas of industrial property law, such as plant breeders rights (Table 6).

These criteria are important when natural genetic resources conserved in situ are employed but not necessarily when ex situ conserved resources are utilized. Moreover, the linkage between the invention and the resources may become weakened sufficiently to be insignificant when active components are isolated or synthesized. However,

In the evolution of patents involving TK-linked knowledge to genetic resources, certain WTO member states "require", disclosure of the origin of this material as well as evidence that previous informed consent of TK holders has been elicited. It is considered an accessory, which relates to the invention collaterally. To do otherwise would constitute fraud and cause the application to be considered an "abuse of rights" (de Carvalho 2000).

Member States that make the Requirement a formal condition of patentability: Andean Community (Bolivia, Colombia, Ecuador, Peru and Venezuela), Costa Rica, Egypt, and India.

Countries that impose the Requirement but not as a formal condition of patentability: People's Republic of China, 15 members of the European community.

Countries that apply the Requirement in the field of patents only: Peru, Egypt, India and the European Community.

Countries that extend the Requirement to other areas of industrial property law: Community of Andean Nations, Brazil, Costa Rica e.g., plant breeder's rights, and where it applies, utility model protection. 
patents in the chemical field may be affected should the Requirement, such as Andean Decision No. 391, which covers genetic resources, derived products, and substances as well, be pertinent to the patent application (de Carvalho 2000, SICE 2005).

\section{Implementation of the Requirement}

The evolution of Andean Decision No. 391 has done much to promote cooperation among neighboring signature countries, namely Peru, Bolivia, Ecuador, Colombia and Venezuela, and has laid the foundation for the development of regional strategies needed to protect their common genetic resources and traditional knowledge. A number of major challenges remain since not all signature countries (e.g., Peru and Ecuador) have yet been able to implement Andean Decision No. 391. So that regulations are consistent and practically applied, progress needs to be made within the Andean Community by promoting the development of appropriate supplementary legislation for the protection of traditional knowledge, standardizing the handling of data and information so that variations in quality are diminished and ways to access are evolved, developing mechanisms to overcome institutional limitations, as well as accommodating interpretative variations to the Decision's intent (Anonymous 1997, Berendson 2000, Molina 2005, SICE 2005).

The Andean Decision evolved out of the Commission of the Cartagena Agreement signed in 1969 (SICE 2005) and involves a trading bloc of South American countries, namely Peru, Ecuador, Bolivia, Colombia, and Venezuela. Formerly referred to as the Andean Pact, it is called the Andean Community of Nations (CAN). This bloc and another referred to as Mercosur, encompass the countries of Brazil, Argentina, Uruguay and Paraguay, and in addition to Chile will become the South American Community of Nations. This is expected to evolve within the next decade into the South American Free Trade Area (SAFTA). Patterned after the European Union, it is likely that harmonization of policies regarding TK-linked genetic resources will take place within this group and eventually with adjacent nations and trading blocs in Central and North America.

As a part of this process, registration of TK knowledge has been proposed. While private registration has its merits in providing protection and enforceability, there are risks to certain time-frame impositions. The burden to communities to legally protect this information may be impractical and the potential always exists that loss of benefits can result from advertent or inadvertent dissemination. When formalities are not imposed, automatic protection may be more difficult to enforce. In countries such as Panama, Peru, Thailand, and the USA, specific criteria regarding protection are outlined whereas other nations may not specify which conditions apply (Africa Model Legislation, Costa Rica, Phillippines) (Alexander et al. 2003, Chanrobles 2004, WIP0 2005b). For example, Costa Rica's sui generis system law of 1998 does not require prior declaration, explicit recognition, or official registration in order to protect the knowledge, practices and innovations of indigenous peoples and communities related to their use of components of biodiversity and associated knowledge (Hansen \& VanFleet 2003).

In Ecuador, a Knowledge Cartel is being devised so that TK is kept in individualized community data banks which are safeguarded from access by others. The intent is to review all the collected knowledge for the purpose of identifying information that is either common to multiple communities or unique. Any distinctive knowledge will be considered a trade secret and any use generated through material transfer agreements or licensing could be used as the source of benefits to be shared by the contributors and the Government of Ecuador (Vogel 1996). This concept has its limitations in not recognizing that commonality is more likely to exist within related clan communities or tribal affiliations and that uniqueness within this context should accommodate a broader benefit base (Elvin-Lewis 2003). It would be a rare event indeed for only one community to have knowledge that is not known to its relatives elsewhere. Usually the utilization of a trade secret is combined with some form of licensing or royalty payment that might extend even if the knowledge enters the public domain (e.g., Listerine) (Hansen \& VanFleet 2003). Also, when such a codicil does not exist, remuneration may still be accrued should a breach of confidence, resulting in its release into the public domain, be linked to malicious intent of the contracting party (WIPO 2002a).

Alternately, when public registration is employed "for the common good," it becomes prior art and thus negates the application of intellectual property rights on TK prior to patent approval. However, placing this knowledge in the public domain can result in the loss of its potential commercial value to community members since it can be used by anyone without permission. For example, in India, an ongoing public registry is taking place called the People's Biodiversity Registers (PBRs) as recognized in the Indian Biological Diversity Bill of 2000 . With the intent of registering this information as prior art, the nation's knowledge of "biodiversity, its usage, trade, and efforts for its conservation and sustainable utilization" is being recorded in computerized data bases. This activity is taking place from the village level upward and is designed to provide information to the public, government, and industry (Hansen \& VanFleet 2003).

The format of this registration and the information provided is not universal. Current databases, including those electronically devised, vary widely in composition and it would be ideal if they were similarly constructed, suitably organized, interactive, and sufficiently large enough to satisfy the need to make "prior art" searches achievable. According to de Carvalho (2003) they "may be the product of creative activity" as related to the original selection and arrangement of data and thus would be protected by 


\section{Elvin-Lewis - Evolving Concepts Related to Achieving Benefit Sharing for Custodians of Traditional Knowledge}

Table 7. Traditional Knowledge protection through Defensive databases.

\begin{tabular}{l} 
Collection and organization of elements of TK in databases in a manner so as to permit their retrieval by trademark \\
and patent examiners in consideration as prior art or as bars to registration. \\
\hline INDIA: Database of traditional Aryuvedic medicine at WIPO website. People's Biodiversity Registers. \\
\hline PEOPLES REPUBLIC of CHINA: Database of traditional medicine at WIPO website. \\
\hline PERU: TK in public domain (collective knowledge) to be submitted to all patent offices worldwide and is voluntary. No \\
safeguards regarding how "secrecy" could be assured for proprietary indigenous databases.
\end{tabular}

PORTUGAL: Permits TK databases to be kept secret, with information protected by unfair competition law, and will not give rise to exclusive rights. What separates TK that is new from TK in the public domain is not the date of disclosure, but the date on which it was first commercially exploited.

SOUTH ASIA: Health Heritage Test Database contains non-patent and patent literature, as prior art, on 50 medicinal plants and their traditional uses.

VENEZUELA: Held secret until appropriate system of TK protection evolves internationally. Biozulua means "house of secrecy" or "house of wisdom" and is protects TK databases of medicinal and agriculture nature. Mechanisms to access have yet to be evolved.

EVOLVING DATABASES: Africa,Australia

copyright according to the Berne convention, Article 2.5, the TRIPS agreement Article 10.2, and the WIPO copyright treaty (WCT) of 1996 (Article 5). With the exception of the European Union, non-original contents of the databases are not protectible. It would be invaluable if specific plant data were comprehensive enough to describe its traditional uses, knowledge or practices, and also provide information on how related taxa within the context of regional biodiversity are used similarly. The design is critical, as is the correctness of the data, in order to satisfy a patent examiner who needs the information in a technically useful manner to determine "novelty." Simply dumping unedited and diffuse information into the patent examiners hands would have little, if any, value. Also, with the everevolving state of data management, consideration should be made to accommodate changes in this technology so that whatever is being stored has long-term accessibility. At this time, WIPO does not warrant "the accuracy reliability, correctness, currency, completeness, or correct translation into English of its current TK databases" evolved from Chinese and Indian sources (www.wipo.org/ipdl/en). Eventually a standard format to complement appropriate electronic data processing might be evolved to make this task easier(WIPO 2002a).

Private database management is particularly problematical since issues to safeguard these data in a defensible manner will always be challenging. A certain level of protection of TK may be afforded through Article 39.3 of the WTO's TRIPS agreement. Article 39 involves issues re- lated to "know how" or trade secrets, and 39.3 concerns governmental obligations to protect undisclosed information from unfair commercial use. However, if these recorded data are not kept within the confines of the indigenous people, protection would be given to the proprietor of the database rather than to them. Losing control of their tangible assets is a major concern since access to this information will always be vulnerable to temporal policies associated with the shifting roles of gatekeepers and key holders and their interpretation of their responsibilities. For purposes of patent examination, it has been suggested by WIPO delegates from Bolivia, Brazil, Panama, and Venezuela, that this aspect be conducted under an obligation of confidentiality (WIPO 2002a). However, when supervision is ceded to governments, there is not any guarantee that their commitment to appropriately administer this information will be honored. This is particularly true if certain administrations prove to be unstable and are subject to self-serving policies and corruption. Within the broad scope of TK, the highly codified and widely documented state of traditional medicine practices may make developing appropriate registries on this aspect easier to achieve (Alexander et al. 2003, de Carvalho 2003). While the intent may exist, the complexities of harmonizing national CK with that of circumscribed or overlapping TK so that benefits are fairly and equitably distributed may be unmanageable. According to Portuguese Decree-Law No. $118 / 2002$, this separation is resolved by identifying the date on which TK is first publicly exploited as having precedence over the date in which public disclosure was

Table 8. Peruvian Traditional Knowledge Laws.

\#26839 - 7/97. Establishes the State's sovereignty with regard to conservation of biodiversity and its sustainable use, but those rights to biological resources does not give the right to genetic resources without state approval. Establishes that TK is cultural patrimony requiring protection.

\#27811 -8/10/2002. Establishes a special protections regime for the collective knowledge of indigenous peoples that is connected with biological resources. Does not affect traditional exchange between indigenous peoples. 
Table 9. Objectives of Peru-Law \#27811. Recognizes rights and power of indigenous peoples to dispose of their TK as they wish.

- To promote respect for and the protection, preservation, wider application and development of indigenous TK.

- To promote the fair and equitable distribution of the benefits derived from the use of that TK.

- To promote the use of the knowledge for the benefit of the indigenous peoples and mankind in general.

- To ensure that use of TK is elicited with prior informed consent.

- To promote the appropriate distribution of benefits within the indigenous context through the creation of an Indigenous Fund.

- To prevent patents being granted without acknowledgement of TK as being a part of prior art in the examination of the novelty and inventiveness through evolution of forms of "protective data bases".

made (de Carvalho 2003). This is an evolving process that is deserving of patience.

\section{Defensive Data Bases}

A number of countries are developing defensive databases to assure that appropriate benefit sharing strategies are evolved for holders of collective knowledge (Table 7). Many, such as the BioZulua (House of Wisdom) in Venezuela, are still being kept secret until an appropriate system of TK protection is evolved internationally. Others, like the new legislation evolved in Peru, namely \#27811 and \#26839 (Table 8), are much more complex. While many of the aspects of \#27811 are to be applauded (Table 9), other features are likely to be problematical and warrant refining (Table 10).

For example, unlike Brazil, for its Afro-Brazilian populations, Peru has yet to address issues of other circumscribed inventive populations within their borders and only defines it in terms of indigenous origins, which refer to populations existing prior to the formation of the Peruvian State, who acknowledge specific tribal affiliations by maintaining distinct cultures, and occupying specific

Table 10. Peruvian Law \#2781: Problematical Areas. territorial areas. These include people in voluntary isolation or those living in rural and native communities. Ethnobotanical data suggests otherwise. The research of Dr. Walter Lewis and myself provides numerous examples from Peru that indicate that access to the same flora, and plant introductions and concepts from elsewhere, have significantly influenced both the indigenous and other unique national pharmacopeias for more than 500 years (Elvin-Lewis et al. 2002, Lewis 2000). Restricting benefits related to the commercialization of $\mathrm{CK}$ to only Peruvian indigenous group merits reconsideration since their will always be challenges to original "inventorship" or added innovations which might not apply to the creative ingenuity of indigenous groups. Therefore, there is a need to affect a logical compromise to accommodate other sources of CK so that distributions of revenues are more equitably achieved. Within this context it is logical that the Indigenous Fund continues to be utilized for its original purpose, but only when proof of indigenous origins for any commercialized CK is clearly evident.

According to current Peruvian law, the bases of revenue for this Indigenous Fund are to be derived from three types of sources. A graded formulation has been devised

Evolution of Defensive Databases: examination of claimed TK as to its novelty: disclosed TK will integrate a public inventory; undisclosed TK will be kept in sequestered databases.

Royalty or Licensing Fees handled by the Peruvian government agency, INDECOPI (Instituto Nacional de Defensa de la Competencia y de la Protecion de la Propiedad Intelectual) are exclusive of collecting fees etc., related to use of natural resources governed by another agency, INRENA (Instituto Nacional de Recursos Naturales).

INDECOPI in Offices of Inventions and New Technology will oversee databases and serve as registry of all contracts and agreements.

- "A percentage which shall not be less than $10 \%$ of the value before tax, of the gross sales resulting from the marketing of goods developed on the basis of collective knowledge."

- The parties may agree on a greater percentage according to the degree of direct use or incorporation of the said knowledge in the resulting end product and the degree to which the said knowledge contributed to the reduction of the cost of R\&D on derived products among other things."

- The licensing agreement shall provide compensation of indigenous people for the use of their collective knowledge ("know-how"); such compensation shall include an initial or monetary or other equivalent payment for sustainable development and a percentage of not less than $5 \%$ of gross sales before tax for the marketing of goods.

- $\quad$ CK in public domain for more than 20 years: $10 \%$

- $\quad$ CK in public domain for less than 20 years: $10 \%+$

- TK not in public domain associated with distinct indigenous group: $10 \%+5 \%$

- Revenue to be placed (exclusively) into Fund for Development of Indigenous Peoples. 


\section{Elvin-Lewis - Evolving Concepts Related to Achieving Benefit Sharing for Custodians of Traditional Knowledge}

in which proprietary TK is valued the highest, but also recognizes that CK that has been known for up to 20 years as having greater value, than others acknowledged as being older. How this might be applied in practice is likely to be challenging. The formulae for acquiring revenue for this fund are based on gross sales, rather than through apportionment of licensing, royalty fees, or net sales of a botanical. While it is conceivable that certain novel botanicals may fit into this category, if sales are locally monitored, oversight of exports that generate revenue may not be readily achieved. Unfortunately, many view this policy as being unrealistic, particularly if the development of a pharmaceutical is involved where lesser percentages are more realistic, and consider it as effectively discouraging commercial investment. In the case of any new pharmaceutical, for example, milestone payments during the evolutionary process, apportionment of royalty revenues, and lower drug costs to the contributing indigenous group or groups may be more pragmatic ways of developing fair compensatory arrangements. Whatever the final outcome, appropriate management of derived revenues is essential and policies which promote control by government agencies, while well intentioned, may not satisfy certain indigenous organizations who may wish to take control of this aspect themselves.

Also, the intent of Peruvians to register national CK in patent offices worldwide, as is being accomplished for the long-established pharmacopeias of India and China, may not be a logical solution to provide protection for its registration as "prior art." Unlike these well-documented traditional systems, Peruvian CK has yet to be similarly assembled. In order to achieve this goal, a commitment of time, effort and money by Peruvian authorities would be required to first collate this information into a suitable and accessible database. Providing data in an unedited form would impose an enormous burden on patent offices that would be unlikely to have the resources to utilize these data as envisioned. Also, like medicinal-plant CK in many South American countries, Peruvian CK is not widely known, but nonetheless may be shared with neighboring countries who are not necessarily members of the Andean community of nations or CAN (e.g., Brazil). Making claim to its exclusivity may invite challenges by other nations who share the same flora, ethnic groups and concepts, and who may prefer to manage this information differently (e.g., Ecuador). An accord is needed within member nations of CAN and other adjacent countries on how this aspect should be managed before registration proceeds. In the interim, since the WIPO requires that patent applications cite the origin of any plant, examiners might request Peru or other adjacent countries to indemnify that a review of their available TK or CK databases has taken place and that linkage to "prior art" does not exist.

As it stands, Peruvian law does not prevent indigenous groups from evolving proprietorial defensive databases which they control. Evoked under prior informed consent, it is possible for information regarding the traditional use of medicinal plants and/or healing ceremonies to be "licensed" as utility linked "know-how" and other data kept secret. The know-how licensing agreement evolved during the ICBG-Peru project is a primary example of how this was achieved between the participating indigenous group and commercial entities. During the medicinal evaluation period of their plant extracts, linked to their TK, participating communities used these milestone payments for educational purposes and capacity building projects, including the training of paraethnobotanists and parataxonomists that could continue the work in the future. Access to this knowledge also provided collaborating scientists with ways to strengthen their investigations by applying suitable disease-targeted assays and phylogenetic amplification techniques. Moreover, acknowledgement of their TK was cited in the preamble of a current pending US patent/s. These concepts served as the template for much of the Peruvian law 27811 as described above.

\section{Institutional Databases}

A number of academic-housed databases have been compiling information on the chemistry, pharmacology, biological activity, taxonomic, geographical distribution, ethnobotanical and ethnomedical uses of a wide variety of natural products and microorganisms. This information, which continues to be regularly compiled from published research papers, is an invaluable resource to the scientific community. These assets enable investigators to conduct suitable dereplications in order to determine the scope of research which has been conducted on particular natural products and their components. The TK that accompanies this information has already been put into the public domain by virtue of publication, and as secondary data its distribution in this manner should not be in contest. The Natural Products Alert (NAPRALERT) at the University of Illinois, Chicago, the CABI Medicinal Plant Database in Wallingford, UK, and MEDLINE are notable examples of those freely accessible sources. In contrast, BioZulua in Venezuela, established by the Fundaciōn para el Desarrollo de las Cienceia Fisicas y Naturales (FUDECI), is proprietary with restricted rights to use (Alexander et al. 2003).

\section{Need for International Repository for TK or CK}

Yet to be addressed by international agencies are ways in which TK or CK (other than Asian Medicinal Systems) might be catalogued independently from national registries. While utilization of WHO and WIPO databases may be appropriate for $\mathrm{CK}$, making sure these data are accurate, interactive and accessible is a massive undertaking. There is a critical need for the creation of a suitable international repository for safeguarding proprietary TK that is now at risk of being lost because certain groups lack the resources for management of these data themselves. In 
Table 11. Currently available Traditional Knowledge Databases.

\begin{tabular}{|ll|}
\hline - & www.worldbank.org/ik \\
- & ip.aaas.org/tekindex.nsf \\
\hline
\end{tabular}

most countries national registries do not exist, and when they do, certain indigenous groups may prefer not to utilize them due to their sense of independence, or lack of confidence in what has evolved. This issue becomes more complex when certain ethnic groups live beyond the borders of one nation. By allowing their data to be stored in this manner, they are also establishing its existence and their "nation state ownership" within a temporal context. Anyone wishing to establish a dialogue with current stakeholders for purposes of accessing this knowledge for potential profitable enterprises would have a way of doing so. For example, based on a pre-arranged fee or other monetary and legal arrangements, restrictive access to their know-how might be permitted so that current stakeholders could benefit directly. Moreover, to reimburse the repository, a user fee might be assessed each time a particular database is used in this fashion. Ultimately, when appropriate policies are evolved, registration within the auspices of the WIPO might be a way of establishing the knowledge as "prior art." A list of currently available databases is provided in Table 11.

\section{Conclusion}

Evolving mechanisms and laws are beginning to impact on how TK and CK can be utilized to achieve appropriate benefits for those who are custodians of these types of information. This is not an easy task since issues related to ownership and ways to ensure appropriate protection, oversight and disbursement of the revenues are always likely to arise. "The premise of biodiversity prospecting is that appropriate policies and institutions are needed to ensure that the commercial value obtained from genetic and biochemical resources are a positive force for development and conservation" (Reid et al. 1993). Much depends upon the application of current national and international laws and the acceptance within and among nations to work towards logical solutions. Critical to this evolving process is the acknowledgement that a great deal of valuable TK is being lost not only by its unsuitable dissemination but because a fitting international repository does not exist to safeguard this knowledge while workable options to address its worth are being examined.

\section{Acknowledgements}

Foremost, I would like to thank Dr. Walter Lewis, who has partnered with me in our studies in ethnobotany for almost four decades. During that time it has been possible to observe and participate in the evolution of the process whereby custodians of traditional knowledge are beginning to benefit from sharing their knowledge with others. Much of what now appears in recent innovations in $\mathrm{Pe}-$

\author{
- www.nuffic.nl/ciran.ik \\ - $\quad$ www.wipo.int/globaltissues/databases/tk/index \\ www.wipo.org/ipdl/en
}

ruvian intellectual property law is the direct result of his leadership in ICBG-Peru and the methods that were developed to define access, prior informed consent, and fair and equitable compensation for those indigenous peoples, particularly the Aguaruna Jivaro, in addition to collaborating Universities in Peru, who also worked to make these agreements possible. Hopefully, this project will serve as a model for others to emulate. I also consider myself fortunate to have taken a course in intellectual property law from Dr. Charles McManis and Dr. N. P. de Carvalho at Washington University. This exposure has enabled me to understand the urgency of the task in identifying workable solutions so that custodians of traditional knowledge can enjoy the benefits they deserve. In addition, I would like to express my appreciation to Mr. Jerzy Koopman LL.M. who has provided me with a needed European perspective and likewise to Ms. Veena Ramani, LL.M. for her thoughtful insights regarding this evolving field.

\section{Literature Cited}

Alexander, M., K. Chamundeeswari, A. Kambu, M. Ruiz, \& B. Tobin. 2003. The role of registers and databases in the protection of traditional knowledge. United Nations University, Institute of Advanced Studies, Tokyo.

Anomymous. 1994. Draft United Nations declaration on the rights of indigenous peoples. Office of the United Nations High Commissioner for Human Rights, Geneva, Switzerland.

Anomymous. 2004a. The Auckland Declaration. Australian Government, Department of Foreign Affairs and Trade.

Anonymous 1995. Provisional application for patent. US Patent and Trademark Office, Washington DC.

Anonymous. 1997. Bolivia common regime for access. Lewis and Clark Law School, Portland, Oregon.

Anonymous. 2002. Bonn Guidelines on Access to Genetic Resources, and Fair and Equitable Sharing of the Benefits Arising out of their Utilization. Convention of Biological Diversity, Conference of the Parties (COP), Decision $\mathrm{VI} / 24$.

Anonymous. 2004b. Peru: Legislation to protect biodiversity restricts patents. World Intellectual Property Report.

Band, J. \& J.S. Gowdy. 1997. Sui Generis database protection. D-Lib Magazine:1-8. 


\section{Elvin-Lewis - Evolving Concepts Related to Achieving Benefit Sharing for Custodians of Traditional Knowledge}

Berendson, B. 2000. Statement by Minister Counsellor Betty Berendson permanent mission of Peru in Geneva.

Bitlaw. 2005. Provisional Patent Application. Bitlaw, A resource on technology law.

Brown \& Michaels. 2005. Frequently Asked Questions about Provisional Applications for Patent. Brown and Michaels.

Chanrobles. 2004. Intellectual Property code of the Phillippines - An overview, Republic Act No., 8293. In Chanrobles Virtual Law Library. Edited by C. Group, Chanrobles Publishing Company.

Chennels, R. 2003. Ethics and practice in ethnobiology, and prior informed consent with indigenous peoples regarding genetic resources. Pp. 1-13 in Biodiversity, Biotechnology, and the Protection of Traditional Knowledge. Edited by C. McManis, Washington University, St. Louis.

de Carvalho, N.P. 2000. Requiring disclosure of the origin of genetic resources and prior informed consent in patent applications without infringing the TRIPS agreement: The Problem and the Solution. Washington University Journal of Law and Policy 2: 371-401.

de Carvalho, N.P. 2003. From the shaman's hut to the patent office; in search of effective protection for traditional knowledge. Pp 1-75 in Biodiversity and Biotechnology and the Protection of Traditional Knowledge. Edited by $\mathrm{C}$. McManis, Washington University, St. Louis.

Elvin-Lewis, M. 2002. Neem: From ethnodentistry to dental products: A review of its antiodontopathic potential. Pp 176-186 in Proceedings of World Neem Conference, 1999. edited by H.M. Behl. Neem Foundation, Mumbai, India., University of British Columbia, Vancouver, B.C. Canada.

Elvin-Lewis, M. 2006. Optimizing the worth of ethnomedical and ethnobotanical data for the discovery of new therapeutics in the Caribbean Basin. Pp. 1-19 in Memorias del XXII Simposio de la Flora y Fauna del Caribe 2003. Universidad de Puerto Rico en Humacoa, Humacoa.

Elvin-Lewis, M. 2005. Safety Issues Associated with Herbal Remedies. Pp. 219-313 in Advances in Food and Nutrition Research. edited by S. Taylor. Elseiver Inc, San Diego.

Elvin-Lewis, M., M. Navarro, A. Colichon \& W.H. Lewis. 2002. Therapeutic Evaluation of Hepatitis Remedies: The Usefulness of Ethnomedical Focusing Techniques. Pp. 270-281 in 7TH International Congress of Ethnobiology 2000. Edited by In: J.R. Stepp, F.S. Wyndham \& R.K. Zarger. University of Georgia Press, Athens, GA.
Gollin, M.A. 1999. Legal consequences of biopiracy. Nature Biotechnology 17:1-4.

Gollin, M.A. 2003. Answering the Call: Public interest intellectual property advisors, biodiversity and biotechnology and the protection of traditional knowledge. Washington University, School of Law, St. Louis, MO.

Hansen, S.A. \& J.W. VanFleet. 2003. Traditional Knowledge and Intellectual Property: A Handbook on Issues and Options for Traditional Knowledge Holders in Protecting their Intellectual Property and Maintaining Biological Diversity. American Association for the Advancement of Science, Washington D.C.

Havemann, P. 1999. Editor of Indigenous People's Rights in Australia, Canada, and New Zealand. Oxford University Press, South Melbourne.

Kaufmann, J.C. \& M. Elvin-Lewis. 1995. Traditional dentistry among pastoralists at Antongobe, NAHALY Plateau, Madagascar. Economic Botany 49:213-222.

Koopman, J. 2005a. Reconciliation of proprietary interests in genetic and knowledge resources: Hurry cautiously! Ecological Economics 53:523-541.

Koopman, J. 2005b. Bumps and bends in the road to intellectual property for traditional knowlege: On knowledge models, legal orders, and the anti-commons in biotechnology. Pp. 247-277 in Molengrafica Series. Intellectual Property Law. Articles on Crossing Borders between traditional and actual, 15. Intersentia, Antwerpen/Oxford.

Koopman, J. 2006. Personal communication.

Ladas \& Perry. 2005. Provisional US Patent Applications.

Lewis, W.H. \& M. Elvin-Lewis. 2003. Medical Botany: Plants Affecting Human Health. John Wiley and Sons, New York.

Lewis, W.H., M. Elvin-Lewis \& D. Fast. 1991. Pentagonia gigantifolia (Rubiaceae) as a snakebite remedy: Empirical methodology functioning in Amazonian traditional medicine. Econonic Botany 45:137-138.

Lewis, W.H., G. Lamas, A. Vaisberg, D.G. Corley, C. Sarasara, M. Elvin-Lewis. 2000. Peruvian medicinal plant sources of new pharmaceuticals (International Cooperative Biodiversity Program-Peru). Pharmaceutical Biology 37S(1999):69-83.

Lewis, W.H. \& V. Ramani. 2003. Ethics and Practice in Ethnobiology: Analysis of the international cooperative biodiversity project in Peru. Pp. 1-18 in Biodiversity, Biotechnology, and the Protection of Traditional Knowledge. Edited by C. McManis, Washington University, St. Louis. 
Lewis, W.H. \& V. Ramani. In Press. Ethics and Practice in Ethnobotany: Analysis of the International Cooperative Biodiversity Group (ICBG) Project in Peru. James \& James/Earthscan, London.

Lewis, W.H., A. Vaisberg, G. Lamas, C. Sarasara \& M. Elvin-Lewis. 2004. Advantage of ethnobotanically-based research for searching new pharmaceuticals. Ethnobotany 16:10-15.

McManis, C. 1998. The interface between international intellectual property and environmental protection: Biodiversity and biotechnology. Washington University Law Quarterly 76:255-279.

McManis, C. 2003. Intellectual property, genetic resources and traditional knowledge protection: Thinking globally acting locally. Cardozo Journal of International and Comparative Law 11:547-581.

McManis, C. In Press. Fitting traditional knowledge protection and biopiracy claims into the existing intellectual property and unfair competition framework. Pp. 425-510 in Intellectual Property and Biological Resources. Marshall Cavendish Academic, Singapore.

Milanowski, D.J., R.E. Winter, M.P. Elvin-Lewis \& W.H. Lewis. 2002. Geographic Distribution of Three Alkaloid Chemotypes of Croton lechleri. Journal of Natural Products 65:814-819.

Molina, P. 2005. Access to genetic resources in the Andean community. Fobomade.

Posey, D.A. \& G. Dutfield. 1996. Beyond Intellectual Property:Toward traditional resource rights for indigenous peoples and local communities. International Development Research Center, Ottawa.

Quinn, M.L. 2001. Protection for Indigenous Knowledge: An international law analysis. St. Thomas Law Review 14:287-313.

Sherman, B. \& L. Bentley. 1999. The Making of Intellectual Property Law. Cambridge University Press, Cambridge. SICE, F.T.I.S. 2005. Decision 391: The commission of the cartagena agreement.

UN. 1994. Draft United Nations declaration on the rights of indigenous peoples:1994/45. Office of the United Nations High Commissioner for Human Rights:, Geneva, Switzerland.

Vogel, J.H. 1995. A market alternative to the valuation of biodiversity: the example of Ecuador. Assocaition of Systematics Collection Newsletter :66-70.
Vogel, J.H. 1996. Case Study 6: Bioprospecting. Biopolicy Journal 2, Paper 5:1-12.

WHO. 2000. General guidelines for methodologies on research and evaluation of traditional medicine. World Health Organization, Geneva, Switzerland.

WHO. 2002. WHO guideline on good sourcing practices (GSP) for medicinal plants (draft). World Health Organization, Geneva, Switzerland.

WHO. 2004a. Guidelines on the Conservation of Medicinal Plants (draft). World Health Organization, Geneva, Switzerland.

WHO. 2004b. WHO guidelines for assessing safety and quality of herbal medicines with reference to contaminants and residues (revised draft). World Health Organization, Geneva, Switzerland.

WIP0. 2005b. WIPO Protection of Traditional Knowledge Genetic Resources, Traditional Knowledge and Folklore, Managing Information News. World Intellectual Property Organization, Geneva.

WIPO. 2002a. Intergovernmental committee on intellectual property and genetic resources, traditional knowledge and folklore. World Intellectual Property Organization, Geneva.

WIPO. 2005b. WIPO committee fails to move on traditional knowledge treaty. World Intellectual Property Organization.

Zhang, X. 2000. Traditional medicine and its knowledge, UNCTAD Expert meeting on systems and national experiences for protecting traditional knowledge, innovations and practices. World Health Organization, Geneva. 